\begin{tabular}{|l|l|l}
\hline Received: Maret 2019 & Accepted: April 2019 & Published : April 2019
\end{tabular}

\title{
Simulasi Lampu Lalu Lintas Simpang Tiga Balikpapan Permai berbasis PLC OMRON CP1E-N30SDR-A
}

\author{
Riza Hadi Saputra ${ }^{1^{*}}$, Ain Sahara ${ }^{2}$, Melinda Greshela ${ }^{3}$ \\ ${ }^{1,2,3}$ Sekolah Tinggi Teknologi Minyak dan Gas Bumi Balikpapan \\ *Email: riza.hadi@sttmigas.ac.id
}

\begin{abstract}
Today on the highway, especially on crossing roads, motor vehicle users are increasing, both motorbike and car drivers. Not only that, it can be seen from the number that has increased greatly every day. This situation requires the existence of a time setting, whose purpose is nothing but to reduce congestion to the risk of accidents. Therefore, in this study, a traffic light simulation is controlled by OMRON CPIE-N3OSDR-A PLC. Traffic light simulation at the three intersections based on PLC OMRON CP1E-N3OSDR-A has been made a traffic light control prototype to set the timing of traffic lights at the three intersections based on OMRON CPIE-N3OSDR-A PLC. The method used for this research is observation, looking for references about sending data at traffic lights and can be processed on PLC systems. Observations were carried out directly at the place of data collection, namely at Simpang 3 Balikpapan Permai. Programming used to instruct traffic light simulations is to use a ladder diagram programming language created using CX-Programmer software. The purpose of this study is to make a traffic light system in the form of a simulation or prototype that has timing from intersection 3 of Balikpapan Permai. In traffic light simulations, timers are needed to synchronize between available intersections, namely 3 intersections. This is so that the vehicle that passes from one intersection where the traffic light conditions at that time is a green light, then the vehicle no longer waits at the next intersection. The signal is sent from one intersection to another as an indicator so that the intersection can automatically adjust the timing of traffic lights.
\end{abstract}

Keywords :Traffic Light Simulation, CX-Programmer, PLC OMRON CPIE-N30SDR-A

\begin{abstract}
Abstrak
Dewasa ini di jalan raya, khususnya di jalan persimpangan, pengguna kendaraan bermotor semakin meningkat, baik pengendara motor ataupun mobil. Tidak hanya itu, dilihat dari jumlahnya pun sudah sangat meningkat setiap harinya. Keadaan ini mengharuskan adanya sebuah pengaturan waktu, yang tujuannya tidak lain untuk mengurangi kemacetan hingga resiko kecelakaan. Oleh karena itu, pada penelitian ini dipaparkan tentang simulasi lampu lalu lintas yang dikendalikan oleh PLC OMRON CPIE-N30SDR-A. Simulasi lampu lalu lintas pada simpang tiga berbasis PLC OMRON CP1E-N3OSDR-A telah dibuat prototipe kendali lampu lalu lintas untuk mengatur pewaktuan lampu lalu lintas pada simpang tiga berbasis PLC OMRON CPIE-N30SDR-A. Metode yang digunakan untuk penelitian ini adalah diantaranya observasi mencari referensi mengenai pengiriman data pada lampu lalu lintas dan dapat diolah pada sistem PLC. Observasi dilakukan langsung pada tempat pengambilan data yaitu di Simpang 3 Balikpapan Permai. Pemrograman yang digunakan untuk menginstruksikan simulasi lampu lalu lintas yaitu menggunakan bahasa pemrograman ladder diagram yang dibuat menggunakan software CX-Programmer. Tujuan dari penelitian ini adalah membuat sistem lampu lalu lintas dalam bentuk simulasi atau prototipe yang memiliki pewaktuan dari simpang 3 Balikpapan Permai.Pada simulasi lampu lalu lintas, timer dibutuhkan untuk melakukan proses sinkronisasi antar persimpangan yang tersedia yaitu 3 persimpangan. Hal ini dimaksudkan agar kendaraan yang melewati dari satu persimpangan dimana kondisi lampu lalu lintas pada saat itu adalah lampu hijau, maka kendaraan tersebut tidak lagi menunggu pada persimpangan berikutnya. Sinyal dikirimkan dari satu persimpangan ke persimpangan lainnya sebagai indikator agar persimpangan tersebut dapat menyesuaikan secara otomatis pewaktuan lampu lalu lintas.
\end{abstract}

Kata kunci : Simulasi Lampu Lalu Lintas, CX-Programmer, PLC OMRON CP1E-N30SDR-A 


\section{PENDAHULUAN}

Saat ini pertumbuhan jumlah kendaraan bermotor semakin meningkat yang mengakibatkan penumpukan pengguna kendaraan bermotor di persimpangan, semakin lama jalanan tersebut dipenuhi oleh kendaraan bermotor, baik mobil maupun motor. Dengan banyaknya kendaraan yang lewat, maka diperlukan suatu alat pengendali yang dapat mengatur keramaian lalu lintas di persimpangan tersebut[1].

Penggunaan lampu lalu lintas adalah salah satu solusi untuk mengurai kemacetan yang terjadi di persimpangan. Dengan sistem buka-tutup disetiap persimpangan diatur kendaraan yang lewat[2]. Adapun tingkat keramaian mempunyai pola yang beragam seperti pada pagi hari terjadi keramaian lalu lintas karena orang-orang berangkat kerja dan siswa pergi ke sekolah, siang hari terjadi keramaian juga pada saat makan siang, dan sore hari pun juga demikian karena orang orang pulang dari kantor untuk menuju rumah masing-masing. Mengatasi hal tersebut, diperlukan adanya fleksibilitas pengaturan waktu lampu lalu lintas yang ada disetiap persimpangan[3].

Kemacetan di persimpangan jalan sudah menjadi santapan sehari-hari bagi pengguna jalan atau pengguna kendaraan bermotor di kota-kota besar[4]. Salah satu cara untuk mengatasi kemacetan tersebut adalah dengan melakukan sinkronisasi lampu lalu lintas yang ada di persimpangan. Hal ini dimaksudkan agar kendaraan yang melewati dari satu persimpangan dimana kondisi lampu lalu lintas pada saat itu adalah lampu hijau, maka kendaraan tersebut tidak lagi menunggu pada persimpangan berikutnya.

Sinyal dikirimkan dari satu persimpangan ke persimpangan lainnya sebagai indikator agar persimpangan tersebut dapat menyesuaikan secara otomatis pewaktuan lampu lalu lintas. Menurut Syukri, kecepataan kendaraan dan jarak antar persimpangan menjadi faktor utama untuk melakukan perhitungan sinkronisasi di persimpangan lampu lalu lintas. Telah dilakukan percobaan sinkronisasi oleh Syukri dimana sinkronisasi ini dapat menghindarkan kendaraan dari lampu merah pada persimpangan lampu lalu lintas secara aktual pada prototipe sebanyak 24 kali dari 30 kali percobaan $(80 \%)$ dengan rata - rata waktu tunggu adalah 12,02 detik, sedangkan secara simulasi sebanyak 17 kali dari 30 kali percobaan $(56,67 \%)$ dengan rata - rata waktu tunggu adalah 1,25 detik[5].

Saat ini perkembangan teknologi semakin pesat sehingga inovasi-inovasi yang baru terus bermunculan. Hal ini juga memberikan kemudahan dalam pekerjaan yang rumit yang biasa dilakukan sehari-hari. Salah satu teknologi tersebut adalah PLC (Programmable Logic Control) dimana alat ini adalah sebagai alat pengendali pada permasalahan yang rumit seperti sinkronisasi pewaktuan lampu lalu lintas[6].

Alat pengendali PLC dalam penggunaanya lebih ringkas dan sederhana karena mempunyai kontak-kontak NO (Normally Open) maupun NC (Normally Close) yang satu paket dengan memory di dalam PLC. Selain itu juga, ada beberapa instruksi yang sering digunakan pada PLC yaitu instruksi timer dan counter. Aplikasi pada lampu lalu lintas persimpangan menggunakan PLC dapat memanfaatkan timer dan counter sebagai instruksi utama dalam prototipe [7].

Sebagai contoh saat lampu hijau menyala di satu persimpangan, maka persimpangan yang lainnya akan menyalakan lampu merah dengan waktu tunda tertentu. Hal ini akan terus berlangsung secara bergantian dari satu persimpangan ke persimpangan lainnya. Menurut penelitian yang dilakukan oleh Antono, bahwa untuk membangun lampu lalu lintas yang asli akan memakan waktu yang banyak sehingga dibuatlah simulasi terlebih dahulu. Sama halnya dengan penelitian yang dilakukan saat ini adalah melakukan simulasi pada Simpang Tiga Balikpapan Permai karena area tersebut sering terjadi kemacetan. Diharapkan dari hasil penelitian ini dapat 
digunakan sebagai referensi untuk pengatur waktu yang tepat pada area tersebut [8].

\section{METODA PENELITIAN}

\section{Alat dan Bahan}

Penelitian ini menggunakan alat pengendali PLC OMRON CP1E-N30SDR-A yang mana dalam alat pengendali tersebut menggunakan Bahasa pemrograman Ladder Diagram[9]. Tempat yang diobservasi adalah lampu lalu lintas di simpang tiga daerah Balikpapan Permai dengan analisa yang dilakukan adalah analisa terhadap waktu pada setiap simpang lampu lalu lintas. Adapun dalam pembuatan simulasi menggunakan alat dan bahan sebagai berikut :

a. Pilot Lamp warna Merah, Kuning, Hijau (masing-masing 3 buah untuk 3 simpang) sesuai dengan keluaran PLC;

b. Push botton 2 buah;

c. Kabel tunggal 10 meter;

d. Papan;

e. PLC OMRON;

f. Kabel PLC;

g. CX-Programmer (software);

h. Driver;

i. KabelMale-Female;

j. Jack Banana; dan

k. Papan LJK.

\section{Diagram Alir dan Diagram Blok}

Metode yang digunakan dalam pembuatan simulasi lampu lalu lintas ini adalah metode pengujian. Dalam metode ini, data yang dikumpulkan dapat dieksplorasi lebih dalam sehingga hasil yang didapatkan maksimal. Studi kasus yang dilakukan yaitu membuat prototipe persimpangan lampu lalu lintas simpang 3 di Balikpapan Permai[10]. Analisa yang dilakukan adalah waktu sinkronisasi secara aktual dan secara prototipe atau simulasi.

Alat yang digunakan dalam prototipe adalah PLC OMRON CP1E-N30SDR-A. Setelah observasi dan simulasi dilakukan, maka selanjutnya adalah membuatnya ke dalam bentuk laporan yang disusun secara rapi. Sehingga dari laporan tersebutdapat dihasilkan sebuah kesimpulan dari penelitian yang telah dilakukan. Agar penelitian berjalan dengan lancar, maka dibuatlah diagram alir cara kerja alat pada Gambar 1.

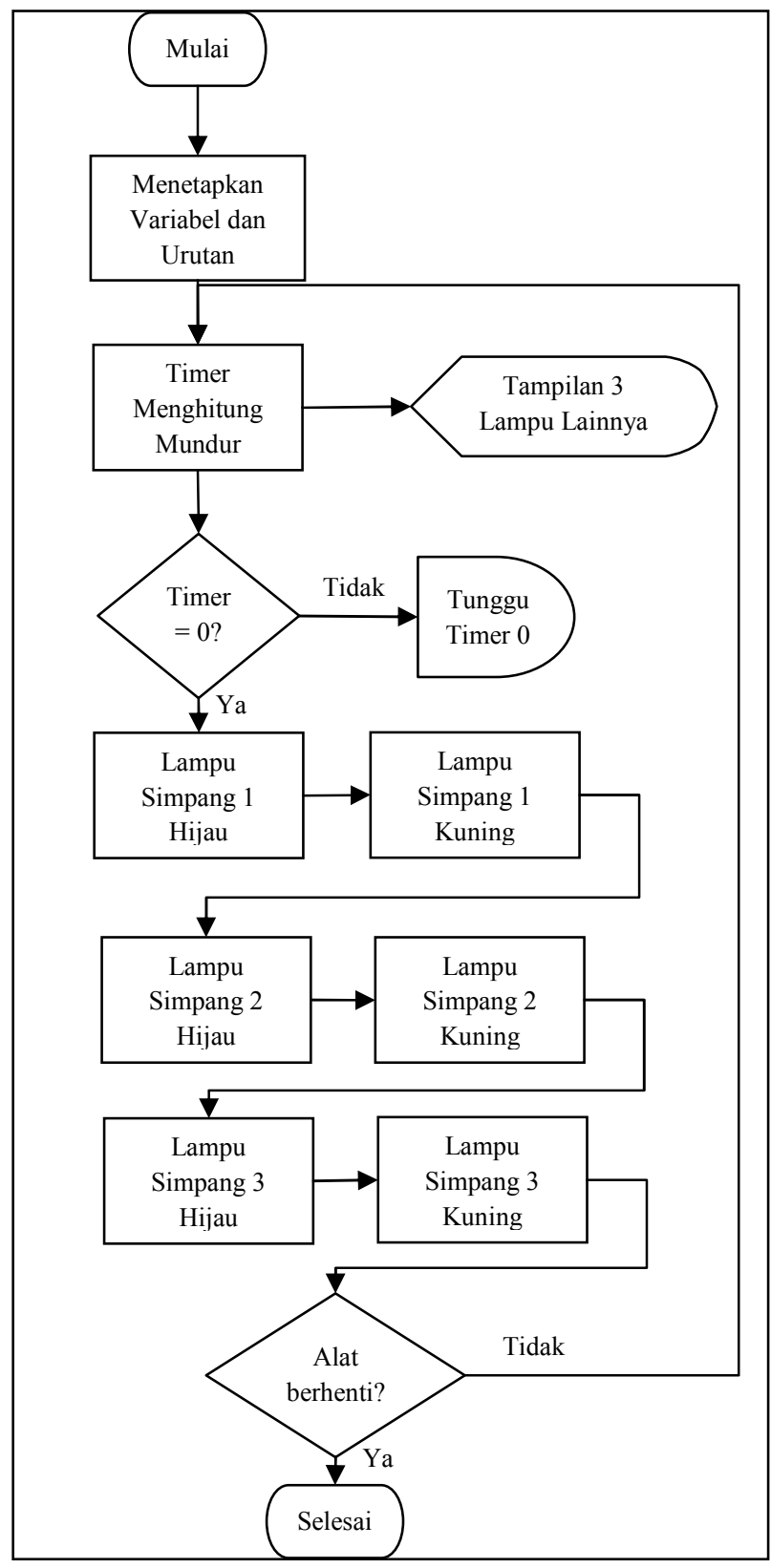

Gambar 1. Diagram Alir Kerja Alat

Berikut adalah penjelasan singkat dari Gambar 1.

a. Menentukan Variabel dan Urutan

Mensinkronkan antara desain wiring dengan desain rancang bangun serta menghubungkan antara kabel pada alat dengan PLC. Kabel dihubungkan dengan 
PLC sesuai dengan masukan dan keluaran masing-masing.

b. Proses pada Timer

Timer akan menghitung mundur sesuai dengan waktu yang telah ditentukan pada ladder diagram. Bisa dilihat pada lampu setiap simpang yang berbeda warna. Ketika timer sudah mencapai batas waktu yang telah ditentukan, jika proses gagal maka proses akan menjadi delay, tetapi jika proses berjalan dengan baik, maka :

- Lampu hijau simpang 1 akan menyala, dan lampu merah pada simpang lainnya akan menyala;

- Lampu kuning simpang 1 akan menyala, dan lampu merah pada kedua simpang lainnya akan menyala;

- Lampu hijau simpang 2 akan menyala, dan lampu merah pada kedua simpang lainnya akan menyala;

- Lampu kuning simpang 2 akan menyala, dan lampu merah pada kedua simpang lainnya akan menyala;

- Lampu hijau simpang 3 akan menyala, dan lampu merah pada kedua simpang lainnya akan menyala;

- Lampu kuning simpang 3 akan menyala, dan lampu merah pada kedua simpang lainnya akan menyala.

Begitulah proses yang akan terjadi secara terus menerus selama tidak ditemukan kendala pada saat proses berjalan.Untuk penjelasan yang lebih teknis mengenai tombol dan lampu yang ada pada alat penelitian, akan dijelaskan pada Gambar 2.

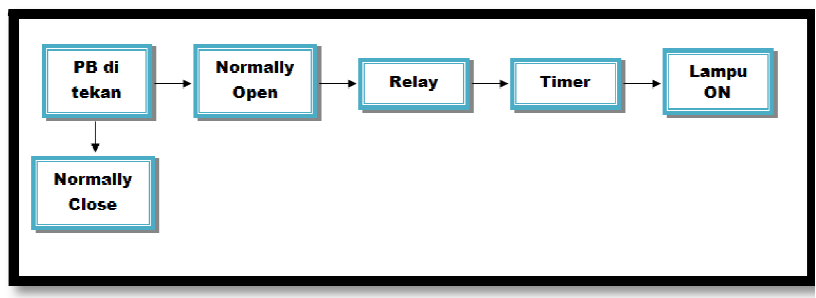

Gambar 2. Diagram Blok

Dari Gambar 2 dapat dijelaskan bahwa dari menekan tombol push buttonhinggalampu berhasil menyala. Bila dijelaskan lebih detail, maka dapat dijabarkan sebagai berikut: a. Push Button (PB)

Simulasi dapat berjalan ketika tombol push button ditekan. Tombol push button terbagi menjadi 2, yaitu push button Normally Open (NO) dan push button Normally Close (NC). Ketika tombol NO ditekan maka proses dapat berjalan, tetapi jika tombol NC ditekan maka proses tidak dapat berjalan.

b. Normally Open (NO)

NormallyOpen (NO) yaitu kondisi awal sebelum diaktifkan akan selalu berada di posisi Open (terbuka). Tombol push button Normally Open adalah tombol untuk menjalankan proses selanjutnya.

c. Relay

Piranti yang digunakan untuk menghubungkan kontaktor yang terdapat didalam PLC. Artinya, setelah tombol NO ditekan, maka relay akan mengubungkan antara NO dengan timer.

d. Timer

Setelah relay berjalan, maka secara langsung timer akan menghitung mundur sesuai waktu yang telah di setting pada ladderdiagram.

e. Lampu $O N$

Pada proses ini, setelah relay menghubungkan kontaktor kemudian timer menghitung mundur, secara bersamaan lampu akan menyala sesuai waktu yang telah ditentukan pada ladder diagram.

f. NormallyClose

NormallyClose (NC) yaitu kondisi awal sebelum diaktifkan akan selalu berada di posisi Close (tertutup). Tombol NC berfungsi untuk menghentikan proses pada simulasi lampu lalu lintas.

\section{HASIL DAN PEMBAHASAN \\ Desain Rancang Bangun Lampu Lalu Lintas}

Desain rancang bangun lampu lalu lintas tampak atas dan tampak samping ditunjukkan pada Gambar 3 dan 4 dan Gambar 5 adalah hasil dari prototipenya. 


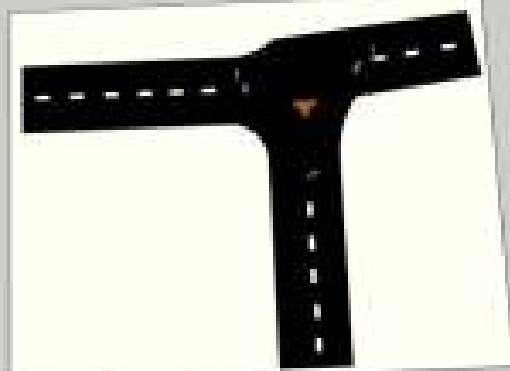

Gambar 3. Desain Rancang Bangun Lampu Lalu Lintas (Tampak Atas)

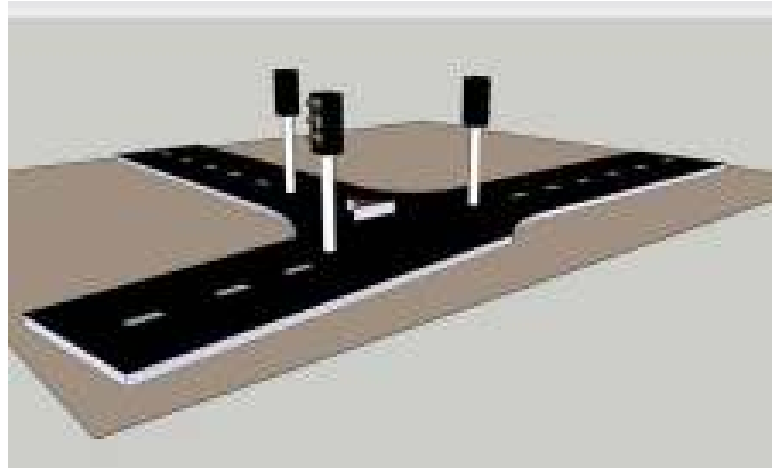

Gambar 4. Desain Rancang Bangun Lampu Lalu Lintas Simpang 3 (Tampak Samping)

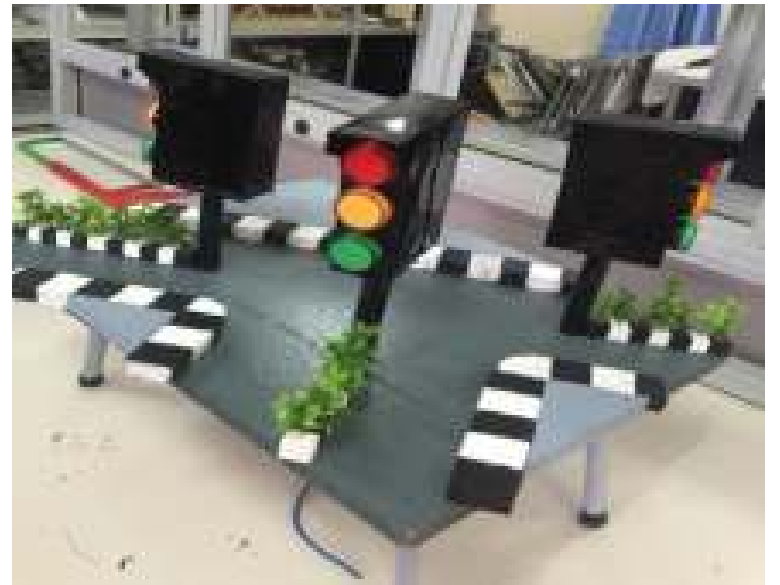

Gambar 5. Prototipe Lampu Lalu Lintas Simpang 3 Balikpapan Permai

Gambar 5 menunjukkan hasil prototipe lampu lalu lintas di Simpang Tiga Balikpapan Permai. Pada prototipe tersebut digunakan 3 lampu tipe pilot dengan warna merah, kuning dan hijau yang mewakili lampu lalu lintas yang sebenarnya.

\section{Desain Lampu Lalu Lintas dengan CX- Designer}

Gambar 6 menunjukkan desain lampu lalu lintas dengan CX-Designer.

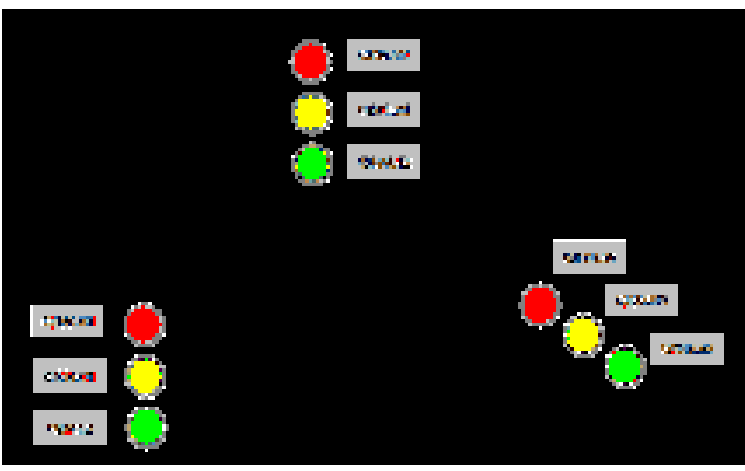

Gambar 6. Desain Lampu Lalu Lintas dengan CXDesigner

Desain ini memperlihatkan cara kerja dari simulasi lampu lalu lintas yang disimulasikan meggunakan aplikasi $C X$ Designer. Pada simulasi lampu lalu lintas yang telah dibuat, ketika dimasukan angka $1(\mathrm{ON})$ pada program, maka relay akan memulai proses pada timer, sehingga timer akan memulai proses menghitung mundur sesuai dengan waktu yang telah ditentukan pada ladder diagram. Bisa dilihat pada lampu setiap simpang yang akan berbeda warna.

Ketika timer sudah mencapai batas waktu yang telah ditentukan, jika proses gagal maka proses akan menjadi delay. Begitulah proses yang akan terjadi secara terus menerus selama tidak ditemukan kendala pada saat proses berjalan.

\section{Desain Wiring Lampu Lalu Lintas}

Desain wiring lampu lalu lintas simpang 3 ditunjukkan pada Gambar 7.

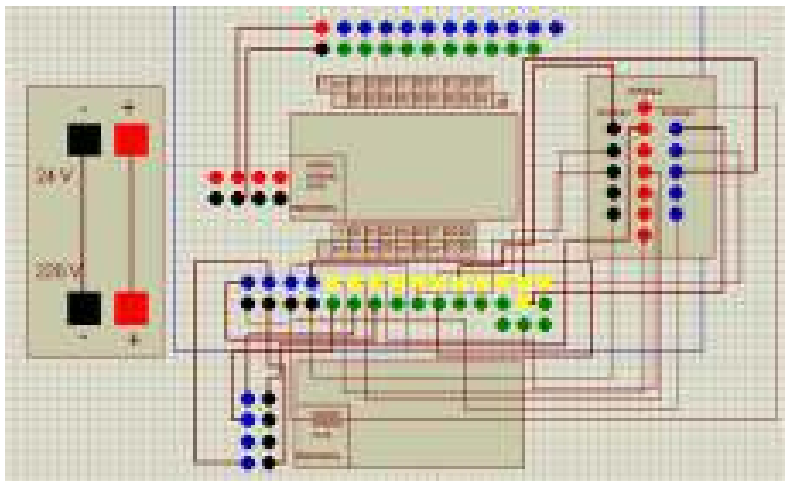

Gambar 7. Desain Wiring Lampu Lalu Lintas Simpang 3 
Berikut ini akan diuraikan pengalamatan wiring PLC pada Gambar 7 sebagai berikut :

a. Port positif $(+)$ dan negatif (-) pada sumber tegangan $24 \mathrm{~V}$ dihubungkan menuju port positif (+) dan negatif (-) pada sumber tegangan $220 \mathrm{~V}$;

b. Port Power supply pada modul terdiri dari port positif $(+)$ dan port negatif (-). Port positif dihubungkan ke positif pada PLC demikian juga port negatif di hubungkan dengan negatif (-) pada PLC;

c. Setelah port positif dan negatif terhubung ke PLC maka power (positif dan negatif) pada sensor dihubungkan ke sesama positif dan negatif pada modul;

d. Menghubungkan semua lampu lalu lintas pada com dan alamat yang sesuai dengan output.

Pengalamatan lampu lalu lintas ke PLC adalah sebagai berikut :

a. Lampu lalu lintas merah pada simpang 1 yang dihubungkan dengan slot PLC dengan alamat Q100.04;

b. Lampu lalu lintas kuning pada simpang 1 yang dihubungkan dengan slot PLC dengan alamat Q100.05;

c. Lampu lalu lintas hijau pada simpang 1 yang dihubungkan dengan slot PLC dengan alamat Q100.03;

d. Lampu lalu lintas merah pada simpang 2 yang dihubungkan dengan slot PLC dengan alamat Q101.03;

e. Lampu lalu lintas kuning pada simpang 2 yang dihubungkan dengan slot PLC dengan alamat Q101.01;

f. Lampu lalu lintas hijau pada simpang 2 yang dihubungkan dengan slot PLC dengan alamat Q101.02;

g. Lampu lalu lintas merah pada simpang 3 yang dihubungkan dengan slot PLC dengan alamat Q100.00;

h. Lampu lalu lintas kuning pada simpang 3 yang dihubungkan dengan slot PLC dengan alamat Q100.01;

i. Lampu lalu lintas hijau pada simpang 3 yang dihubungkan dengan slot PLC dengan alamat Q100.02.
Desain Ladder Diagram dengan CXProgrammer

Ladder diagram rung 0 sampai dengan 2 yang didesain menggunakan aplikasi $C X$ Programmer ditunjukkan pada Gambar 8 sampai 14.

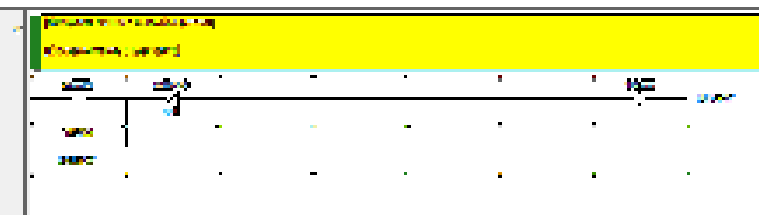

Gambar 8. Rung 0 (Relay)

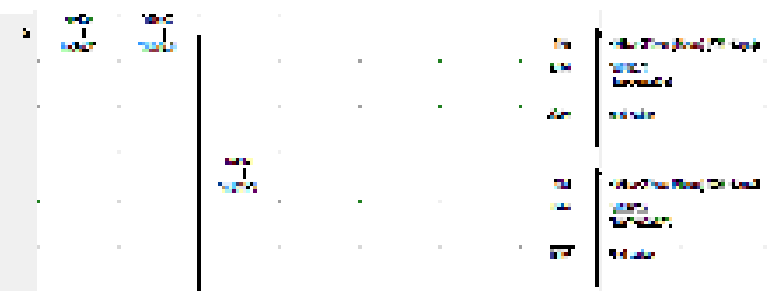

Gambar 9. Rung 1 (Timer 1 dan Timer 2)

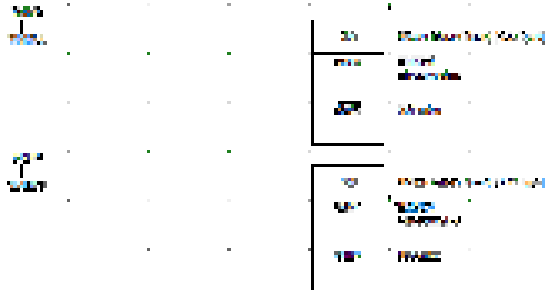

Gambar 10. Rung 1 (Timer 3 dan Timer 4)

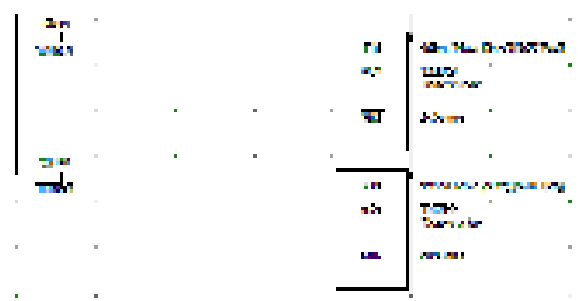

Gambar 11. Rung 1 (Timer 5 dan Timer 6)

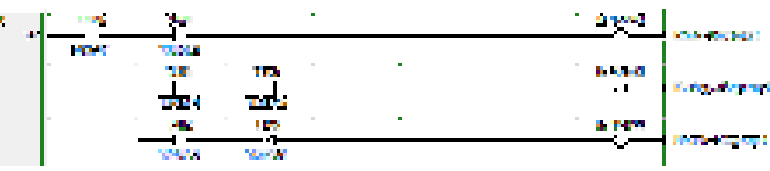

Gambar 12. Rung 2 (Output Simpang 1)

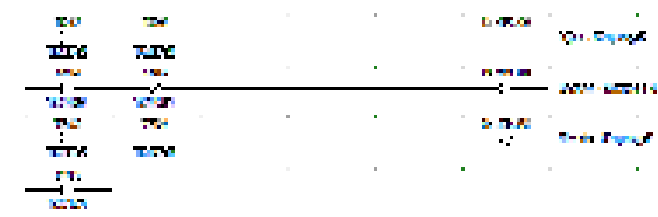

Gambar 13. Rung 2 (Output Simpang 2) 


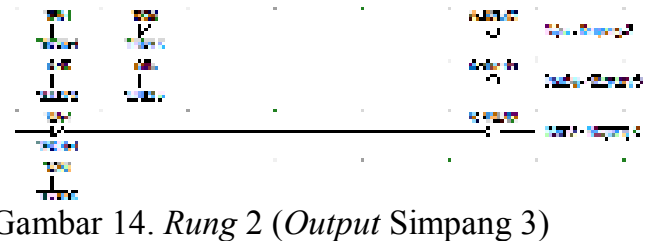

Gambar 14. Rung 2 (Output Simpang 3)

Dalam simulasi lampu lalu lintas, proses yang terjadi dapat dibaca dengan bahasa pemrograman ladder diagram. Berikut ini adalah penjelasan tentang bagaimana cara membaca proses yang terjadi pada saat simulasi lampu lalu lintas berjalan dengan bahasa pemrograman ladder diagram.

Proses simulasi lampu lalu lintas dapat dilakukan dengan memasukan nilai input pada ledder diagram. Secara bersamaan ketika memasukan nilai 1 (ON) maka akan mengakibatkan relay menjadi Close. Ketita relay dalam keadaan close maka akan menghidupkan timer 1 (TIM 0001) selama 20 detik. Ketika timer 1 dalam keadaan close maka secara bersamaan akan menghidupkan lampu lalu lintas, seperti:

a. Lampu lalu lintas (simpang 1) hijau akan menyala;

b. Lampu lalu lintas (simpang 2) merah akan menyala;

c. Lampu lalu lintas (simpang 3) merah akan menyala.

Ketika timer sudah terpenuhi pada TIM 0001, maka timer 1 akan menghidupkan timer 2 (TIM 0002) selama 10 detik. Ketika timer 2 dalam keadaan close maka secara bersamaan akan menghidupkan lampu lalu lintas, seperti:

a. Lampu lalu lintas (simpang 1) kuning akan menyala;

b. Lampu lalu lintas (simpang 2) merah akan menyala;

c. Lampu lalu lintas (simpang 3) merah akan menyala.

Setelah timer sudah terpenuhi pada TIM 0002, maka timer 2 akan menghidupkan timer 3 (TIM 0003) selama 20 detik. Ketika timer 3 dalam keadaan close maka secara bersamaan akan menghidupkan lampu lalu lintas, seperti:

a. Lampu lalu lintas (simpang 1) merah akan menyala; b. Lampu lalu lintas (simpang 2) hijau akan menyala;

c. Lampu lalu lintas (simpang 3) merah akan menyala.

Ketika timer sudah terpenuhi pada TIM 0003, maka timer 3 akan menghidupkan timer 4 (TIM 0004) selama 10 detik. Ketika timer 4 dalam keadaan close maka secara bersamaan akan menghidupkan lampu lalu lintas, seperti:

a. Lampu lalu lintas (simpang 1) merah akan menyala;

b. Lampu lalu lintas (simpang 2) kuning akan menyala;

c. Lampu lalu lintas (simpang 3) merah akan menyala.

Setelah timer sudah terpenuhi pada TIM 0004, maka timer 4 akan menghidupkan timer 5 (TIM 0005) selama 20 detik. Ketika timer 5 dalam keadaan close maka secara bersamaan akan menghidupkan lampu lalu lintas, seperti:

a. Lampu lalu lintas (simpang 1) merah akan menyala;

b. Lampu lalu lintas (simpang 2) merah akan menyala;

c. Lampu lalu lintas (simpang 3) hijau akan menyala.

Setelah timer sudah terpenuhi pada TIM 0005, maka timer 5 akan menghidupkan timer 6 (TIM 0006) selama 10 detik. Ketika timer 6 dalam keadaan close maka secara bersamaan akan menghidupkan lampu lalu lintas, seperti:

a. Lampu lalu lintas (simpang 1) merah akan menyala;

b. Lampu lalu lintas (simpang 2) merah akan menyala;

c. Lampu lalu lintas (simpang 3) kuning akan menyala.

Proses ini akan berlangsung secara berulang dengan syarat selama proses berjalan nilai input tidak boleh berubah atau tetap bernilai $1(\mathrm{ON})$, tetapi proses ini dapat terhenti apabila nilai input berubah menjadi0 (OFF), artinya nilai 0 (nol) dapat menghentikan proses yang berlangsung pada simulasi lampu lalu lintas ini. Berikut Tabel 1 adalah tabel keterangan simbol pada ladder diagram. 
Tabel 1. Tabel Keterangan Simbol pada Ladder Diagram

\begin{tabular}{lll}
\hline No. & Simbol & Penjelasan \\
\hline 1. & m000 & Input \\
\hline 2. & m0001 & Trigger pass (safety) \\
\hline 3. & 10.00 & Relay \\
\hline 4. & TIM 0001 & Timer 1 \\
\hline 5. & TIM 0002 & Timer 2 \\
\hline 6. & TIM 0003 & Timer 3 \\
\hline 7. & TIM 0004 & Timer 4 \\
\hline 8. & TIM 0005 & Timer 5 \\
\hline 9. & TIM 0006 & Timer 6 \\
\hline 10. & 100.03 & Lampu Hijau Simpang 1 \\
\hline 11. & 100.04 & Lampu Merah Simpang 1 \\
\hline 12. & 100.05 & Lampu Kuning Simpang1 \\
\hline 13. & 101.02 & Lampu Hijau Simpang 2 \\
\hline 14. & 101.01 & Lampu Kuning Simpang 2 \\
\hline 15. & 101.03 & Lampu Merah Simpang 2 \\
\hline 16. & 100.02 & Lampu Hijau Simpang 3 \\
\hline 17. & 100.01 & Lampu Kuning Simpang 3 \\
\hline 18. & 100.00 & Lampu Merah Simpang 3 \\
\hline & & \\
\hline
\end{tabular}

\section{KESIMPULAN}

Pada penelitian ini telah dirancang simulasi lampu lalu lintas 3 simpang yang berbasis PLC OMRON CP1E-N30SDR-A. Dari hasil pengamatan yang dilakukan, maka didapatkan kesimpulan sebagai berikut:

a. Sebelum proses simulasi lampu lalu lintas berjalan, terlebih dahulu menentukan variabel serta menghubungkan antara wiring dengan rancang bangun pada PLC. Kabel dihubungkan dengan PLC sesuai dengan input dan output masing-masing. Memasukan bahasa pemrograman berupa ladder diagram melalui aplikasi CXProgrammer. setelah terhubung maka dapat kita memberikan nilai input pada ledder diagram, dan ketika nilai 1 telah dimasukan, maka relay akan menghubungkannya dengan timer, sehingga timer dapat menghitung mundur sesuai waktu yang telah ditentukan. Secara bersamaan lampu akan menyala sesuai waktu yang telah ditentukan pada ladder diagram. Proses ini akan berulang secara terus menerus jika tidak ditemui perubahan pada nilai input selama proses berjalan, atau tidak terdapat kendala lainnya. b. Bahasa pemrograman ladder diagram dapat dibuat sesuai dengan proses yang terjadi dan sesuai dengan instruksi seperti dalam hal ini adalah simulasi lampu lalu lintas.

c. Pada simulasi lampu lalu lintas, timer dibutuhkan untuk melakukan proses sinkronisasi antar persimpangan.Hal ini dimaksudkan agar kendaraan yang melewati dari satu persimpangan dimana kondisi lampu lalu lintas pada saat itu adalah lampu hijau, maka kendaraan tersebut tidak lagi menunggu pada persimpangan berikutnya. Sinyal dikirimkan dari satu persimpangan ke persimpangan lainnya sebagai indikator agar persimpangan tersebut dapat menyesuaikan secara otomatis pewaktuan lampu lalu lintas.

\section{SARAN}

Saran dari penelitian ini adalah membuat simulasi lampu lalu lintas yang melebihi dari simpang 3 yaitu simpang 4 atau simpang 5 karena semakin banyak persimpangan, maka semakin kompleks juga pengaturan dalam perangkat keras dan lunaknya.

\section{DAFTAR PUSTAKA}

[1] Y. Irnaldi, A. Apwiddhal, and L. Utama, "Kajian Kinerja Persimpangan Tidak Bersinyal Studi Kasus Simpang Tiga Parak Laweh Banuaran Kota Padang," Abstr. Undergrad. Res. Fac. Civ. Plan. Eng. Bung Hatta Univ., vol. 1, no. 1, pp. 1-12, 2015.

[2] R. Firmansyah, F. Baskoro, and B. R. Rynaldo, "Perancangan dan Simulasi Sistem Lampu Lalu Lintas 4 Arah dengan Menggunakan Programmable logic Controller Omron CP1E dengan Tampilan Cx," Indones. J. Electr. Electron. Eng., vol. 1, no. 2, pp. 13-18, 2018.

[3] E. Harahap, A. Suryadi, R. Ridwan, D. Darmawan, and R. Ceha, "Efektifitas Load Balancing Dalam Mengatasi Kemacetan Lalu Lintas," J. Mat. Univ. Islam Bandung, vol. 16, no. 2, pp. 1-7, 2017.

[4] F. Kurniawan, "Implementasi Model Simulasi Sistem Dinamis Terhadap Analisis Kemacetan Lalu Lintas Dikawasan Pintu Masuk Pelabuhan Tanjung," J. Penelit. 
Transp. Darat, vol. 20, no. 1, pp. 1-8, 2018.

[5] S. H. K. Pasaribu and A. Dharmawan, "Rancang Bangun Sinkronisasi Pewaktuan Lampu Lalu Lintas Menggunakan PLC Omron CPM2A Dan Wonderware Intouch," EKSPLORA Inform., vol. 4, no. 1, pp. 93-104, 2014.

[6] P. Gunoto, M. Irsyam, and T. K. Wijaya, "Pengembangan Sistem Traffic Lights Berdasarkan Kepadatan Kendaraan Menggunakan PLC," J. Dimens. Univ. Riau Kepul., vol. 4, no. 3, pp. 1-12, 2015.

[7] K. Jordan, "Miniatur Pengendali Lampu Lalu Lintas Berdasarkan Panjang Antrian Kendaraan Berbasis Programmable Logic Controller (PLC)," 2018.
[8]

D. Antono, "Lampu Pengatur Rambu Lalu Lintas Portable dengan Menggunakan Kendali Logika Terprogram," J. Tek. Elektro Politek. Negeri Semarang, 2016.

[9] T. Dwinugroho and P. Upy, "Perancangan Program dan Simulasi Smart Traffic Light Menggunakan Programmable Logic Control (PLC)," 2017.

[10] D. Hendarto and I. S. Hidayat, "Prototype Sistem Traffic Light Simpang Empat dengan Kontrol Jarak Antrian KendaraanBerbasis PLC," J. Tek. Elektro Sains JUTEK Univ. Ibn Khaldun, vol. 3, no. 1, pp. 1-9, 2016. 